Bisset, K. A. \& Hale, C. M. F. (1960). J. gen. Microbiol. 22, 536-538

\title{
Flagellar Pattern and Growth of Bacillus spp.
}

\author{
By K. A. BISSET and C. M. F. HALE \\ Department of Bacteriology, University of Birmingham
}

\begin{abstract}
SUMMARY: Observations by electron microscopy and by light microscopy of material stained to demonstrate flagella and cell walls, simultaneously, showed that in non-filamentous Bacillus spp. the flagella of growing bacilli were usually fully developed towards one pole, and developed on the other pole as the process of fission advanced. This is similar to the condition in other types of bacteria, previously described, and is in accordance with the theory that bacterial reproduction is not by simple fission, but by production of a bud from a mother cell.
\end{abstract}

Observations upon Gram-negative bacteria (Bisset, 1951) and motile Grampositive cocci (Hale \& Bisset, 1958) showed that in these organisms the flagella were retained upon the mother-cell when fission occurred, and that the daughter-cell or bud was devoid of flagella or had them in an early stage of development. Experiments with strains of Salmonella and Proteus, where the development of flagella was inhibited by a slightly increased temperature, confirmed this hypothesis (Bisset \& Pease, 1957). There is also evidence that one of the two halves of a bacterium in course of fission is physiologically younger than the other, this being the putative daughter-cell (Pennington, 1950; Hale \& Bisset, 1958). None of these observations upon flagella, however, have included Gram-positive bacilli, although the results of Pennington and of Hale \& Bisset indicate that by the physiological tests they may be expected to behave like the Gram-negative forms, as do the motile cocci. The purpose of this paper is to extend these observations to species of Bacillus.

\section{METHODS}

Observations were made upon two strains of filamentous cereus-type bacilli and three non-filamentous strains of subtilis-type; i.e. of rough and smooth morphology respectively. These were isolated in the laboratory and grown on nutrient agar at $25^{\circ}$. They were examined at ages varying from 4 to $48 \mathrm{hr}$., either by electron microscopy or by a variant of the staining method of Hale \& Bisset (1958), in which $1 \%$ methylene blue was substituted for crystal violet.

\section{RESULTS}

On the filamentous cereus-type bacilli the flagella were rather rare and irregularly distributed, giving no clue to their development (Pl. 1, fig. 1). On the individual subtilis-type bacilli, the number of flagella was very variable, from one or two up to about 100, in specimens from the same sample; but whether few or many, their arrangement, in actively growing cultures, was always similar. The flagella were much more numerous towards one end and 
at one pole of the bacillus than at the other (Pl. 1, figs. 2-4; Figs. 1, 2). Where the number of flagella was large (Pl. 1, fig. 2) they covered most of the cell wall, but in most cases still left one pole exposed. Where the number of flagella was small (Pl. 1, fig. 3) they were often confined to one half of the

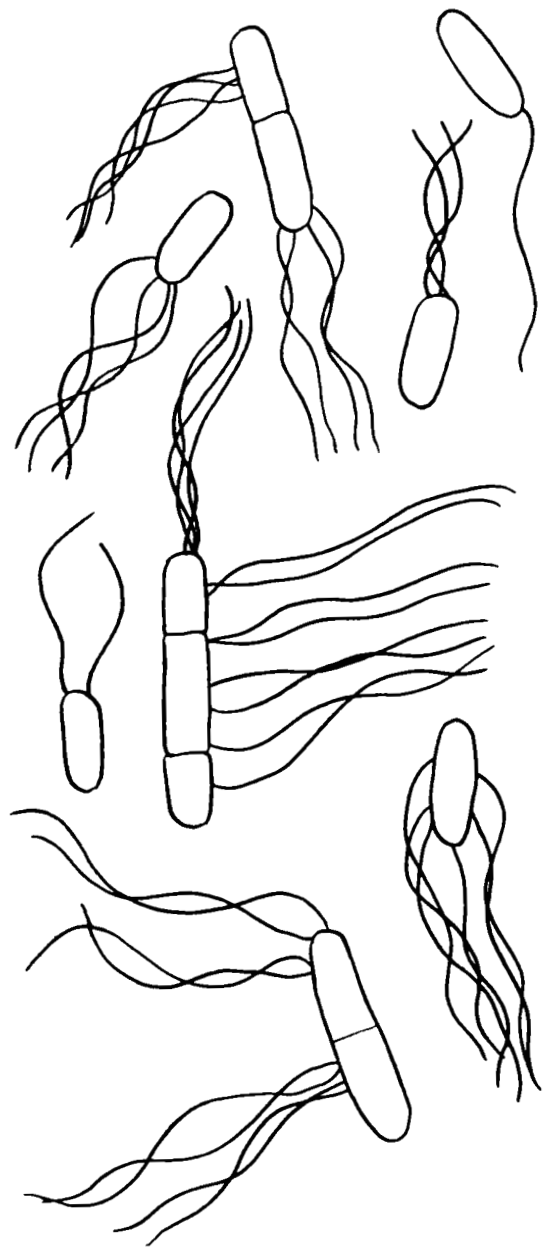

Fig. 1

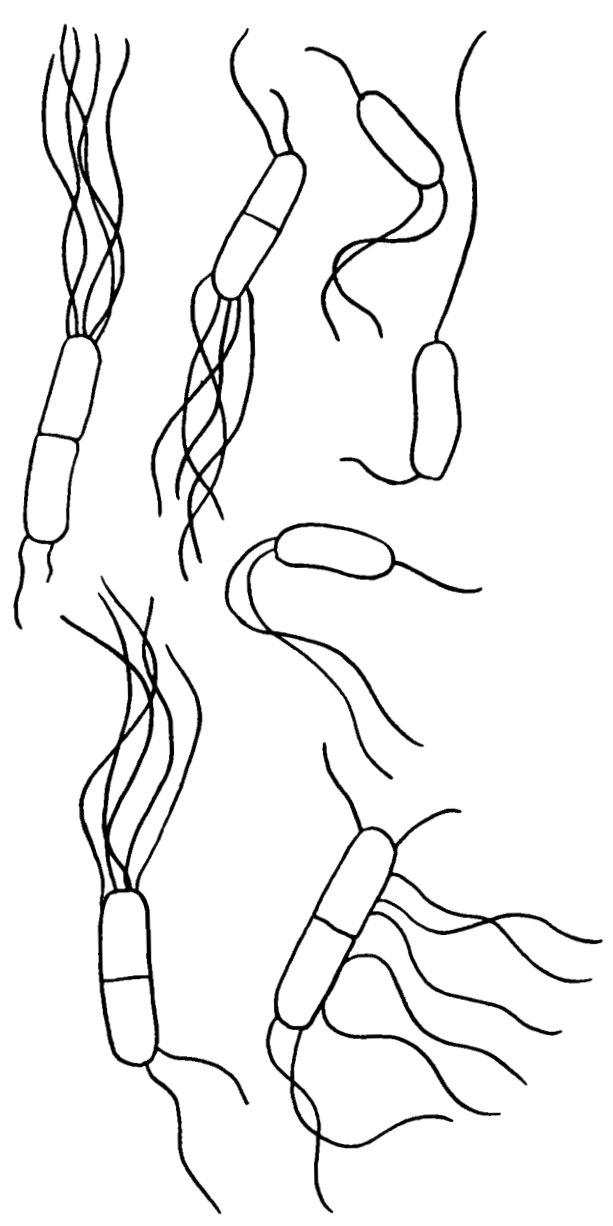

Fig. 2

Fig. 1. Bacilli of subtilis-type, drawn from preparations stained to demonstrate flagella and cell wall simultaneously, showing the concentration of flagella at one pole.

Fig. 2. As Fig. 1, showing flagella at an early stage of development on the second pole.

bacillus; the drawings of stained preparations in Fig. 1 show a variety of such appearances. Where flagella had begun to appear at the second pole ( $\mathrm{Pl}$. 1, fig. 4) these were much fewer or less well developed; the drawings of stained preparations in Fig. 2 show a variety of such appearances. 


\section{DISCUSSION}

The arrangement of flagella in the filamentous ('rough') bacillus of the cereustype affords no information about the mode of development of the cells themselves. But in the case of the individual bacilli of the 'smooth' subtilis-type the arrangement is comparable with that seen in Gram-negative bacilli and motile cocci, and is in accordance with the theory that the main growth of the cell envelope is towards one pole of the bacillus, so that the mature flagellate cell wall is retained at one end, and a new growth, upon which the flagella have not yet had time to grow, is formed at the other. These observations thus support the general concept that non-filamentous bacteria reproduce vegetatively, not by true binary fission, but by budding.

\section{REFERENCES}

BissET, K. A. (1951). The development of surface structures on dividing bacteria. J. gen. Microbiol. 5, 156.

Bisset, K. A. \& Pease, P. E. (1957). The distribution of flagella in dividing bacteria. J. gen. Microbiol. 16, 382.

Hale, C. M. F. \& Bisset, K. A. (1958). The pattern of growth and flagellar development in motile Gram-positive cocci. J. gen. Microbiol. 18, 688.

Pennington, D. (1950). The reaction of bacterial cells with formaldehyde. J. Bact. 59,617 .

\section{EXPLANATION OF PLATE 1}

All electron micrographs, gold-shadowed.

Fig. 1. Filaments of bacilli of cereus-type, showing rather scanty flagella in an irregular arrangement. $\times 10,000$.

Fig. 2. Bacillus of subtilis-type with numerous flagella arising from all parts of the cell wall except for one pole. $\times 20,000$.

Fig. 3. Bacillus of subtilis-type with few flagella, arranged peritrichously on one half of the rod and one pole. $\times 15,000$.

Fig. 4. Bacillus of subtilis-type in process of fission (budding) showing several flagella near one pole and a single one at the other. $\times 15,000$.

(Received 28 September 1959) 
Journal of General Microbiology, Vol. 22, No. 2
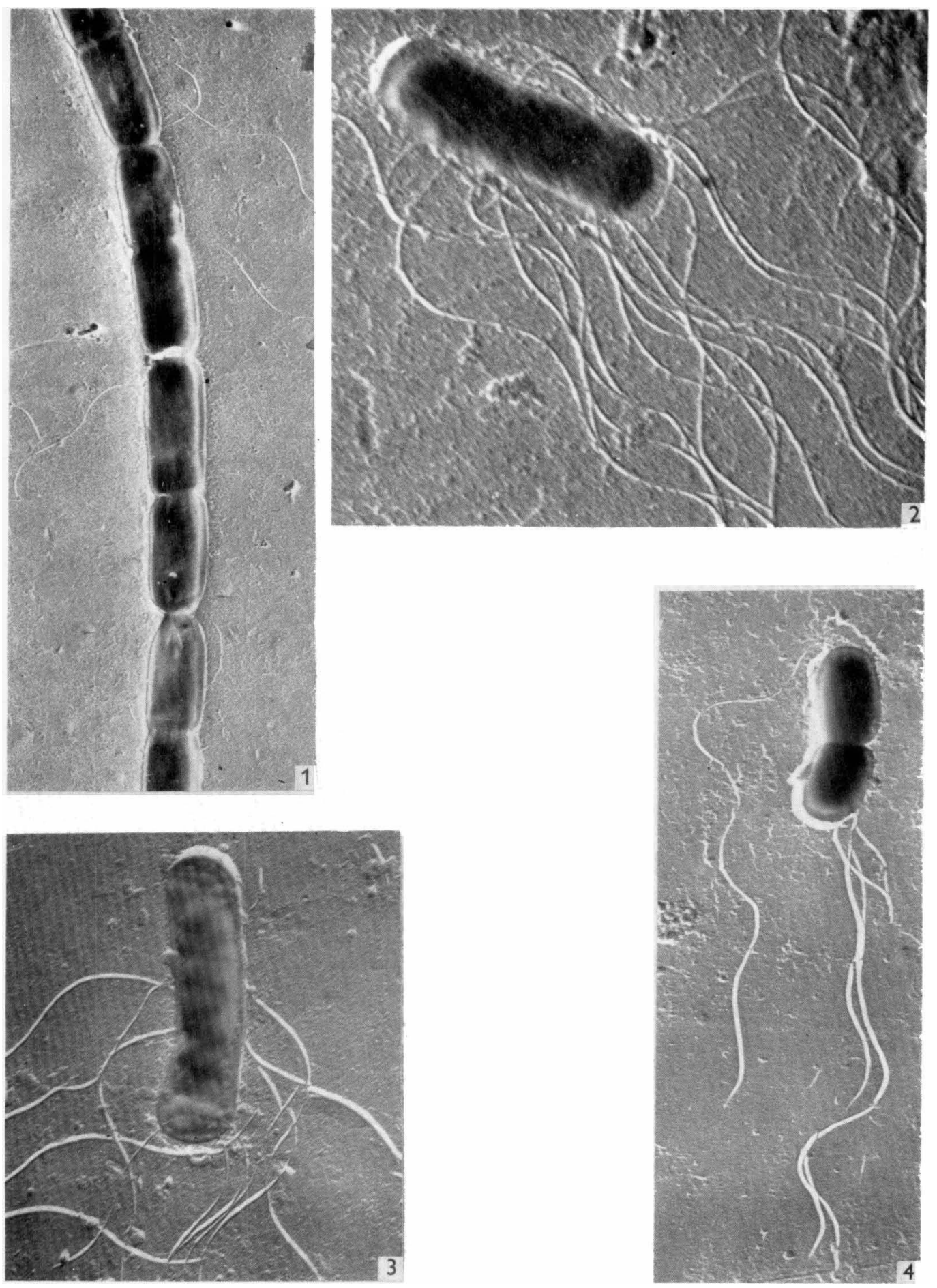

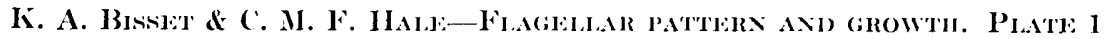

